\title{
Effect of Self-Management Program on the Patient' Knowledge and Practice Regarding Stoma Care
}

\author{
Hanan Ali Ibrahim Almanzalawi. \\ Lecturer of Medical-Surgical nursing, Faculty of Nursing, Mansoura University, Egypt.
}

\begin{abstract}
The aim of the study was to evaluate the effectiveness of self-management program on the patients' knowledge and practice regarding stoma care. Methods: A purposeful sample consisted of 90 adults with stoma was examined. A pre/post quasi-experimental research design was followed. The setting: The general surgery department and adult surgery outpatient Clinic in Damietta University Hospital. Data collection tools included a structured interview questionnaire (demographic data of patients, their medical history, and their knowledge about stoma), and an observational checklist to assess the patients' practices regarding stoma care. In addition to a self-management program. Results: The mean age of the studied adults was $47.9 \pm$ years. Two-thirds of participants were males $(65 \%)$ and educated ( $67 \%)$. About two thirds of them $(63 \%)$ had bowel cancer, and the majority (94\%) had no family history of stoma. There was a highly significant difference in the patients' levels of knowledge in pre/immediate, post, and after one month of discharge $(\mathrm{P}<0.001)$. There was a highly significant improvement in the patients' level of practice regarding procedures of stoma care in pre/immediate, post, and after one month of discharge $(\mathrm{P}<0.001)$. Conclusions: The studied adult patients' knowledge and practice regarding stoma care significantly improved after exposure to the self-management program. Recommendations: Adult patients with stoma should receive adequate and continuous education regarding ostomy self-care, lifestyle changes, and self-efficacy. Medical and surgical nurse should provide the adult patient with adequate knowledge, and training about stoma care.
\end{abstract}

\section{Keywords: Self-management Program, Stoma Care, Adult Patients, Knowledge \& Practice.}

\section{Introduction}

Stoma is an artificial communication between organs or viscera and the external environment for draining, evacuation, or nutrition. There are many different conditions or reasons for creating an ostomy (National Cancer Institute, 2017).

With increasing incidences of colorectal cancer and urinary cancer, teaching clients about stoma care, given by enterostomal therapists and nurses during post-operative and discharge periods, enables them to increase self-efficacy in ostomy management. There are many gastrointestinal/genitourinary causes that may necessitate the creation of fecal or urinary diversion. These may include colostomy for colonrectal cancer, diverticular disease, inflammatory bowel disease, intestinal obstruction, gastrointestinal trauma, and gynecological cancers (Beitz, 2004).

Stoma has several negative adverse effects on patients; physical, psychological, and social. The physical problems include leakage, bad odor, peristomal skin problems, adaptation for stoma appliances, adaptation for clothing, and the presence and site of the stoma which have a significant effect on the patient's daily life (Andrade et al., 2016).

It is generally understood that a stoma has a negative effect on people's quality of life. This negative impact can affect self-care practices that may result in inappropriate and costly use of supplies. Stoma care self-efficacy is essential as adult patients have the ability to manage their stoma to minimize and prevent adverse outcomes (Ran et al., 2016).

The minimum post-operative care and skill set for patients with an ostomy include their ability to manipulate the pouch clip or spout if present and empty the pouch independently. Additional skills that are needed to be taught include bathing and clothing and activity restrictions. Moreover, it is important to teach patients to know the influence and prescription of medications of ostomy function, as well as the effect of diet on it. Other skills to be taught include peristomal skin care, odor control, preventing complications, and sexual counseling. Any failure to achieve normal activity influences life and may lead to long treatment and complications and its long-term consequences (American Cancer Society, 2017).

Living with a stoma requires that the adult patient learns about self-management skills. However, many health-care providers must give the stoma-related knowledge and skills to provide education and clinical support to enable clients to make informed decisions, achieve their goals, and overcome barriers of effective self-management. Self-management program education includes patient education, helping them to practice it (Culha et al., 2016).

The nurse can play an important role in caring for colostomy patients. This may be achieved by the bedside nurse working with an enterostomal therapist or a clinical specialist nurse with stoma care 
experience. Nurses are the main key and have the most important role in health teaching for supporting and persuading patients in performing self-care. They act as health educators in almost all health care settings to develop and promote patient health literacy and assist patients in taking control and becoming familiar with their condition (Fulham, 2018).

\section{Significance of the Study}

Stoma has a negative effect on the physical and functional status following stoma surgery (Salvadalena, 2008). Stoma self-care is associated with higher health-related quality of life scores. In addition, there are many series of self-care problems that should be identified during post-colostomy patients (Ran et al., 2016).

In recent years, the number of patients undergoing ostomy has been increasing year by year. The existence of stoma seriously affects the physiological function, psychological state and social adaptability of patients, such as the feelings of worry and fear related to altered patients' body image, decreased social activities, loss of body function, withdrawal, and economic pressure. This reduces the quality of life of the stoma population. Stoma patients generally lack knowledge of stoma and self-management skills. Poorly educated patients do not have a good grasp of stoma self-care techniques. Therefore, positive and effective patient education can effectively improve patients' self-management ability. Provision of information regarding the patient's health condition, post-operative progress and stoma education is very important to ensure optimal adjustment (Sunny \& Monica, 2019).

\section{Aim of the Study}

The current study aimed to assess the effectiveness of self-management program on adult patients' knowledge and practice regarding their stoma care through the following specific objectives:

1. Assessing the adult patients' knowledge regarding stoma care.

2. Assessing the adult patients' practices regarding stoma care and their self-management.

3. Implementing a self-management program for adult patients with stoma to improve their knowledge and self-management regarding stoma care.

4. Evaluating the effectiveness of the selfmanagement program on improving adult patients' knowledge regarding stoma care practice.

\section{Research Hypotheses}

1. Adult patients' knowledge, post being exposed to stoma care self-management program, will improve.

2. Adult patients' practice, post being exposed to stoma care self-management program, will improve.

\section{Subjects \& Methods}

A pre/post quasi-experimental research design was utilized in the current study. The study was conducted at the general surgery department and adult surgery outpatient clinic in Damietta University Hospital. A purposive sample of 90 adult patients with stoma, who were admitted to the previously mentioned setting, was included.

The inclusion criteria included adult patients with stoma. The exclusion criteria included patients who suffered from other physical or psychological problems that would prevent them from participating in self-care.

Tools and techniques of data collection

Tool (I): A structured interview questionnaire was designed by the researcher in simple Arabic language after reviewing related literature. It included the following parts:

- Demographic data: age, gender, level of education, and residence.

- Medical history: previous hospitalization, cause of stoma, and family history.

- Assessment of adults' knowledge about the stoma: It included 10 items related to definition, types, causes, indications for stoma, complications, type of diet, type of clothes to be worn, prescribed food, precautions that should be followed during food intake, and sources of patients' knowledge.

The total patients' knowledge percentages were calculated for known and unknown answers. Each complete correct answer was given (2 marks), each incomplete correct answer was given (1 mark), and (zero mark) was given for wrong or unknown answers. For each area of knowledge, the scores of the items were summed up and the total answers were divided by the number of the items, giving a mean score for the knowledge. Then, these scores were converted to a percentage score.

\section{Scoring of responses}

\section{The total scores of participants' knowledge were} graded as follows:

- Good: Scores $\geq 65 \%$

- Fair: 50-65\%

- Poor: $<50 \%$

- An observational checklist: It contained 12 items including intervention toward dealing with patients' stoma, such as skin care around stoma, regular nutrition, and hygiene care.

As for the patients' practice, each item that was completed correctly was scored (2), each item that was not complete was scored (2), and each incorrect item was scored (zero). For each area, the scores of the items were summed up, and the total was divided 
by the number of the items, giving the mean score for the part. These scores were converted to a percentage score.

The total scores of participants' practice was graded as follows:

- Good: Scores $\geq 65 \%$

- Fair: $50-65 \%$

- Poor: $<50 \%$

\section{Pilot study}

It was carried out on $10 \%$ of the adult patients $(\mathrm{N}=9)$, for the purpose of modification, clarification, and estimation of the time needed for data collection. The designed tools were tested on those patients. Unclear items were clarified, unnecessary items were omitted, and new items were added. Those who shared in the pilot study were not included in the study sample.

\section{Field work}

At the beginning of the interview, the researcher introduced herself to the participants and then explained the purpose of the study. The participants were reassured that all gathered information is confidential. The title and objectives of the study were illustrated as well as the main data items to be covered and the study was carried out after obtaining the necessary official approvals.

Each patient was interviewed individually. The purpose of the interview was to fill out the preprogram application questionnaire and the observation checklist to assess stoma care practice. These tools were used three times. First, they were used as a preprogram application tool for assessment of patients' knowledge and practices regarding their stoma. Then, they were used again as immediate post-program application tool. Finally, they were employed again for repeated follow-up after one month to evaluate the effect of self-management program. Confidentiality of obtained information was assured. The average time spent for each patient for completion of each interview for knowledge was around 30-45 minutes, whereas the time needed for practice was 45-60 minutes. Data were collected over a period of 6 months; May to October 2019.

Moreover, a self-management program, with an Arabic handout provided, was constructed by the researcher after reviewing related literature, based on the level of patients' knowledge and practice according to deficit needs about stoma and the care needed. This program included the following:

Preparatory phase: A review of local and international literature related to the research task was carried out.

Program construction: The program was constructed according to the needs obtained from pre-program assessment using the interviewing questionnaire, observational checklist as well as a literature review which aimed to improve the studied patients' deficits in knowledge and practice regarding stoma care. It was designed in English and was translated into Arabic. The content of the program included simple and clear information about stoma to meet the patients' needs and their level of understanding. The self-care management program was introduced to adult patients as handouts in printed form material. It included pictures with colors to guide and encourage adult patients to perform their care independently. It contained purpose, objectives, and health care. It was prepared in a user-friendly way to be understood easily by the adult patients in self-care.

The program included two parts. Firstly, the theoretical part included the following items; purpose and care of colostomy, daily life change, diet, elimination, traveling preparations and follow-up, complications, and unusual signs around stoma. Secondly, the practical part covered the following items; measuring stoma size, emptying and changing stoma pouch, and peristomal skin care and hygiene.

The design of the program was based on the adult patients' knowledge regarding stoma care. The program contained four sessions; three sessions for the theoretical part and one session for the practical part. The duration of each theoretical session ranged from 30-45 minutes, whereas the time needed for each practical session was from 45-60 minutes, based on the knowledge of each session. The first session included an opening ceremony, a pre-test, and the presentation of the program aims. The second session focused on the knowledge regarding stoma care; definition, signs and symptoms, types and causes, etc. The third session focused on the knowledge regarding stoma self-care methods. The fourth session focused on the evaluation of the program and the distribution of the post-test.

\section{Steps of program construction General Objectives}

The aim of this program was to improve the adult patient's knowledge and practice regarding stoma care. Specific Objectives

By the end of this program, each adult patient should be able to:

- Define stoma.

- Enumerate causes of stoma.

- Mention indications for stoma.

- List types of stoma.

- Determine complications of stoma.

- Identify the nursing role.

- Discuss parents' role at home.

- Apply self-care interventions regarding the protection of the skin around the stoma, hygiene, diet, and infection prevention. 
a- The educational program scheduling

\begin{tabular}{|c|c|c|c|}
\hline Session No. & Time & Contents & Methods of teaching \\
\hline $\begin{array}{l}\text { The first } \\
\text { session }\end{array}$ & $\begin{array}{l}-10 \text { min. } \\
-30-45 \text { min. for } \\
\text { each adult patient } \\
-10 \mathrm{~min} .\end{array}$ & $\begin{array}{l}\text { - Communication with the adult patients } \\
\text { - Discussion with them about the following } \\
\text { items: } \\
\text { oDefinitions of stoma } \\
\text { o Causes of stoma } \\
\text { o Indications for stoma. } \\
\text { - Open discussion }\end{array}$ & $\begin{array}{l}\text { - Handout booklet } \\
\text { - Open discussion } \\
\text { - Demonstration } \\
\text { - Re demonstration }\end{array}$ \\
\hline $\begin{array}{l}\text { The } \\
\text { second } \\
\text { session }\end{array}$ & $\begin{array}{l}-10 \text { min. } \\
-30-45 \text { min. for } \\
\text { each adult patient } \\
-10 \text { min. }\end{array}$ & $\begin{array}{l}\text { - Discussion with the adult patients about the } \\
\text { previous session } \\
\text { - Discussion with them about the following } \\
\text { items: } \\
\text { o Types of stoma } \\
\text { o Complications of stoma } \\
\text { oSteps of the nursing role } \\
\text { - Open discussion }\end{array}$ & $\begin{array}{l}\text { - Handout booklet } \\
\text { - Open discussion }\end{array}$ \\
\hline $\begin{array}{l}\text { The third } \\
\text { session }\end{array}$ & $\begin{array}{l}-10 \text { min. } \\
-45-60 \text { min. for } \\
\text { each adult patient }\end{array}$ & $\begin{array}{l}\text { - Discussion with the adult patients about the } \\
\text { previous session } \\
\text { - Discussion with them about the following } \\
\text { items: } \\
\text { o The parents' role at home } \\
\text { o Applying child self-care interventions } \\
\text { regarding the protection of the skin } \\
\text { around the stoma } \\
\text { O Steps of infection prevention } \\
\text { O Types of prescribed diet } \\
\text { - Open discussion }\end{array}$ & $\begin{array}{l}\text { - Handout booklet } \\
\text { - The picture included } \\
\text { in the booklet } \\
\text { - Open discussion } \\
\text { - Demonstration } \\
\text { - Re demonstration } \\
\text { - Real equipment }\end{array}$ \\
\hline $\begin{array}{l}\text { The fourth } \\
\text { session }\end{array}$ & $\begin{array}{l}-45-60 \text { min. for } \\
\text { each adult patient } \\
-10 \text { min. }\end{array}$ & $\begin{array}{l}\text { - Focusing on the evaluation for the program } \\
\text { and the distribution of the post-test. } \\
\text { - Open discussion }\end{array}$ & $\begin{array}{l}\text { - Handout booklet } \\
\text { - The picture included } \\
\text { in the booklet } \\
\text { - Open discussion } \\
\text { - Demonstration } \\
\text { - Re demonstration }\end{array}$ \\
\hline
\end{tabular}

Program implementation: The implementation of the program was carried out at the previously mentioned setting. The subject material was collected by interviewing each patient individually. Approximately three to four cases were interviewed weekly with a total of ninety patients. Those interviews were conducted on two days a week, Sundays and Mondays, from 9:00-11:00 am for a period of six months. Those days were selected because they were the most suitable for pre-operative and post-operative. The researcher should assess the participants' knowledge and practice regarding stoma care, and supplied the stoma adult patient with the needed knowledge and practice through note book and oral discussion during the interview sessions the researcher used media, such as videos, PowerPoint presentations, and simulations in the practical sessions to improve attention. Moreover, the researcher provided some counseling to adult patients via telephone. Each session started with a summary of what has been discussed in the previous session. Each adult patient was able to use the Arabic handout as a reference if needed at home.

Program evaluation: Before the implementation of the program, a pretest was conducted for the adult patients regarding knowledge and practice. At the end of the sessions, the evaluations of the educational selfstoma management were administered after the implementation of the program. A post-test was conducted for the adult patients regarding knowledge and practice in the same format of the pretest to evaluate the effectiveness of the implemented program; this was conducted immediately after the 
program and then was repeated after one month during the outpatient care follow-up.

Tool validity and reliability

Tools Validity

Content validity of the study tools was determined by a panel of five experts in medical-surgical nursing and community health nursing. Modifications of these tools were carried out regarding to the panel judgment on clarity of sentences, appropriateness of the content, and accuracy of scoring and recording of items.

Tools Reliability

The study tools' reliability was estimated through Pearson's Correlation Coefficient Test to assess the correlation between variables. The validity and reliability findings suggested that the tools utilized could be used as valid and reliable data collection tools for the present study.

\section{Ethical consideration}

An official approval was obtained from the administrators of the study setting to carry it out there. A clear explanation about the nature, importance, and expected outcomes of the present study was given to the administrators. All patients were informed about the aim of the current study, its benefits, and data collection tools to obtain their acceptance and cooperation. The researcher informed them that they voluntarily had the right to withdraw from the study at any time without giving any reason and that their responses would be held confidentially.

\section{Statistical design}

The collected data were reviewed, prepared for computerized data entry, coded and scored, and then analyzed and tabulated. Data entry and analysis were done using SPSS (Statistical Package for Social Sciences) version17.0. The data were expressed as means, SD, and percentage distribution using Mann Whitney Test to determine the significance of the numeric variables and Chi Square to determine the significance of the non-parametric variables. The study used the Paired T Test to compare between the pre and post program evaluations and the Pearson's Correlation Coefficient Test to assess the correlation between the numeric variables in the same group. The $\mathrm{P}$-values that were less than 0.05 were considered as statistically significant.

\section{Results}

Table (1): Frequency and Percentage distribution of the studied adult patients by their demographic characteristics $($ No. $=90)$.

\begin{tabular}{|c|c|c|}
\hline Characteristics of adults & No. $=90$ & $\%$ \\
\hline $\begin{array}{l}\text {-Age (years) } \\
\cdot 21-30 \\
\cdot 30-40 \\
\cdot 40-50 \\
\cdot 50-60\end{array}$ & $\begin{array}{c}19 \\
32 \\
35 \\
4\end{array}$ & $\begin{array}{c}21.71 \\
35.14 \\
39.15 \\
5.0\end{array}$ \\
\hline \multicolumn{3}{|c|}{ Age (years) Mean is 47.9 \pm} \\
\hline $\begin{array}{ll}\text {-Education } \\
\text { - } & \text { Illiterate } \\
\text { - } & \text { Read \& write } \\
\text { - } & \text { Primary education } \\
\text { - } & \text { Preparatory education } \\
\text { - } & \text { Secondary education } \\
\text { - } & \text { University education } \\
\end{array}$ & $\begin{array}{c}31 \\
11 \\
13 \\
18 \\
13 \\
4\end{array}$ & $\begin{array}{c}33.0 \\
12.0 \\
15.0 \\
20.0 \\
15.0 \\
5.0\end{array}$ \\
\hline $\begin{array}{c}\text { - Residence } \\
\text { • Urban } \\
\text { • Rural }\end{array}$ & $\begin{array}{l}33 \\
57\end{array}$ & $\begin{array}{l}37.15 \\
62.85\end{array}$ \\
\hline
\end{tabular}




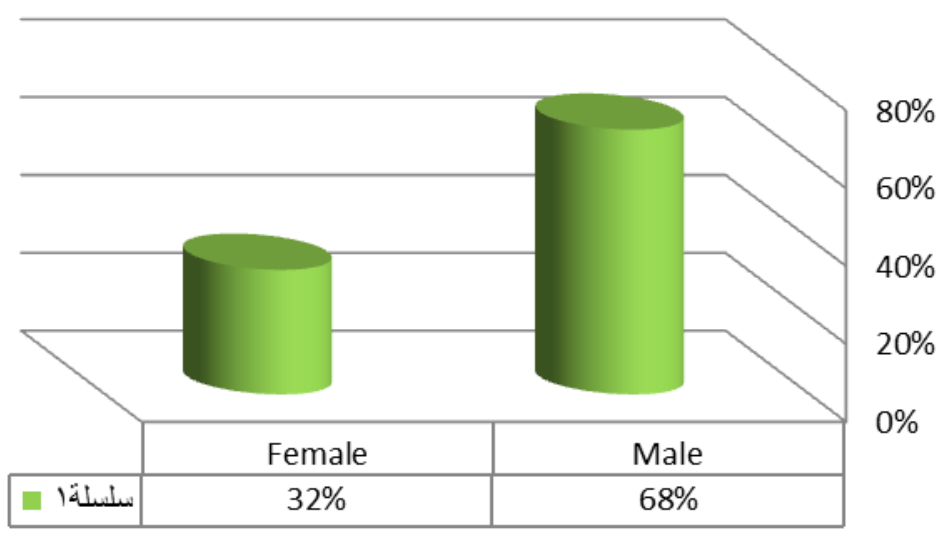

Figure (1): Percentage and distribution of adult patients with stoma according to their gender.

Table (2): Frequency and percentage of distribution of studied adults regarding their medical history (No.= 90).

\begin{tabular}{|l|c|c|}
\hline \multicolumn{1}{|c|}{ Items } & No. & \% \\
\hline Causes of stoma: & 56 & 63.0 \\
- Bowel cancer & 16 & 18.0 \\
- Diverticular disease & 6 & 7.0 \\
- Ulcerative colitis & 2 & 2.0 \\
- Crohn's disease & 5 & 6.0 \\
\hline Family history: & 85 & 94.0 \\
- Yes & & 26.0 \\
- No & 23 & 74.0 \\
\hline Adults'previous hospitalization: & 67 & \\
- Yes & & \\
- No & & \\
\hline
\end{tabular}

Table (3): Distribution of studied adults' knowledge regarding stoma pre, immediate post, and after one month discharge of program implementation.

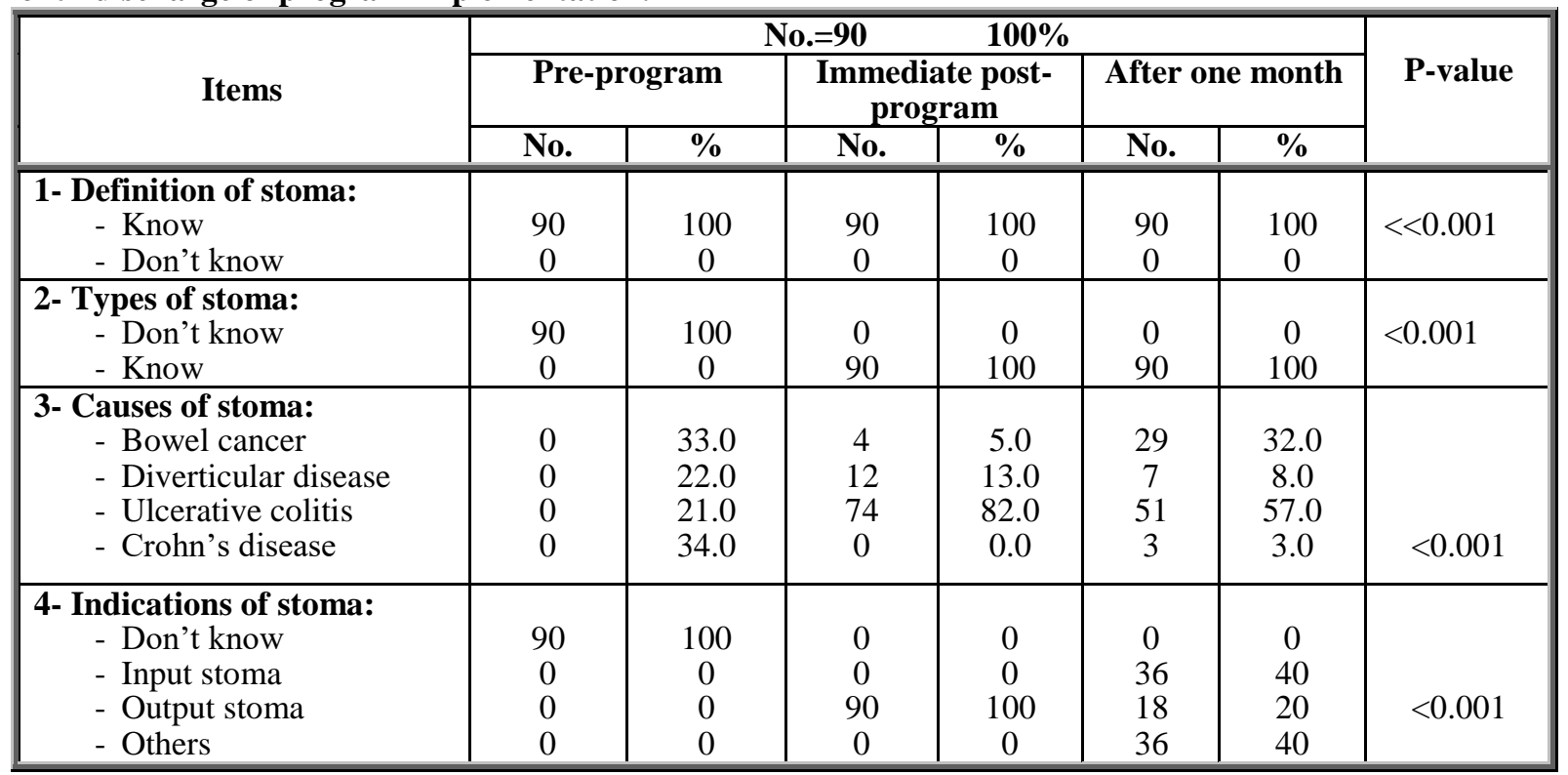




\begin{tabular}{|c|c|c|c|c|c|c|c|}
\hline \multirow{3}{*}{ Items } & \multicolumn{6}{|c|}{ No. $=90$} & \multirow{3}{*}{ P-value } \\
\hline & \multicolumn{2}{|c|}{ Pre-program } & \multicolumn{2}{|c|}{$\begin{array}{c}\text { Immediate post- } \\
\text { program }\end{array}$} & \multicolumn{2}{|c|}{ After one month } & \\
\hline & No. & $\%$ & No. & $\%$ & No. & $\%$ & \\
\hline $\begin{array}{l}\text { 5- Complications: } \\
\text { - Don’t know } \\
\text { - Know }\end{array}$ & $\begin{array}{c}90 \\
0\end{array}$ & $\begin{array}{c}100 \\
0\end{array}$ & $\begin{array}{c}7 \\
83\end{array}$ & $\begin{array}{c}8.0 \\
92.0\end{array}$ & $\begin{array}{l}18 \\
72\end{array}$ & $\begin{array}{l}20 \\
80\end{array}$ & $<0.001$ \\
\hline $\begin{array}{l}\text { 6-Types of diet: } \\
\text { - Don't know } \\
\text { - Easily digested } \\
\text { - Warm food } \\
\text { - Balanced diet } \\
\end{array}$ & $\begin{array}{l}90 \\
0 \\
0 \\
0 \\
\end{array}$ & $\begin{array}{c}100 \\
0 \\
0 \\
0\end{array}$ & $\begin{array}{c}0 \\
78 \\
3 \\
9 \\
\end{array}$ & $\begin{array}{c}0 \\
87.0 \\
3.0 \\
10.0 \\
\end{array}$ & $\begin{array}{c}0 \\
15 \\
32 \\
43\end{array}$ & $\begin{array}{c}0.0 \\
17.0 \\
35.0 \\
48.0\end{array}$ & $<0.001$ \\
\hline $\begin{array}{l}\text { 7-Types of clothes to be } \\
\text { worn: } \\
\text { - Don't Know } \\
\text { - Cotton clothes }\end{array}$ & $\begin{array}{l}77 \\
22\end{array}$ & $\begin{array}{l}85.7 \\
14.3\end{array}$ & $\begin{array}{c}0 \\
90\end{array}$ & $\begin{array}{c}0 \\
100\end{array}$ & $\begin{array}{l}36 \\
54\end{array}$ & $\begin{array}{l}40 \\
60\end{array}$ & $<0.001$ \\
\hline $\begin{array}{l}\text { 8-Precaution to follow } \\
\text { during food intake: } \\
\text { - Don't Know } \\
\text { - Know }\end{array}$ & $\begin{array}{c}90 \\
0\end{array}$ & $\begin{array}{c}100 \\
0\end{array}$ & $\begin{array}{c}0 \\
90\end{array}$ & $\begin{array}{c}0 \\
100\end{array}$ & $\begin{array}{l}12 \\
78\end{array}$ & $\begin{array}{l}12.9 \\
87.1\end{array}$ & $<0.001$ \\
\hline $\begin{array}{l}\text { 9- Prescribed food: } \\
\text { - Don’t Know } \\
\text { - Balanced \& easy } \\
\text { digested }\end{array}$ & $\begin{array}{c}90 \\
0\end{array}$ & $\begin{array}{c}100 \\
0\end{array}$ & $\begin{array}{c}0 \\
90\end{array}$ & $\begin{array}{c}0 \\
100\end{array}$ & $\begin{array}{l}12 \\
78\end{array}$ & $\begin{array}{l}12.9 \\
87.1\end{array}$ & $<0.001$ \\
\hline $\begin{array}{l}\text { 10- Source of } \\
\text { knowledge about } \\
\text { care: }\end{array}$ & \multicolumn{4}{|c|}{ No. } & \multicolumn{3}{|c|}{$\%$} \\
\hline $\begin{array}{l}\text { - No knowledge } \\
\text { - Doctor\& nurse } \\
\text { - Only nurse } \\
\text { - Only doctor }\end{array}$ & \multicolumn{4}{|c|}{$\begin{array}{c}8 \\
38 \\
31 \\
13 \\
\end{array}$} & \multicolumn{3}{|c|}{$\begin{array}{l}9.0 \% \\
42.0 \% \\
35.0 \% \\
14.0 \% \\
\end{array}$} \\
\hline $\begin{array}{l}\text { 11- Mean of knowledge } \\
\text { scores pre, immediate, and } \\
\text { post program (Mean } \pm \text { SD) } \\
16.42 \pm 12.71\end{array}$ & \multicolumn{2}{|c|}{$1.00 \pm 0.00$} & \multicolumn{2}{|c|}{$47.28 \pm 1.63$} & \multicolumn{2}{|c|}{$43.26 \pm 3.83$} & $<0.001$ \\
\hline
\end{tabular}

$* * * A$ highly statistical significant difference $(P<0.001)$ 
Table (4): Comparison of adult patients' levels of knowledge related to their stoma pre, immediate post, and after one month of program implementation discharge.

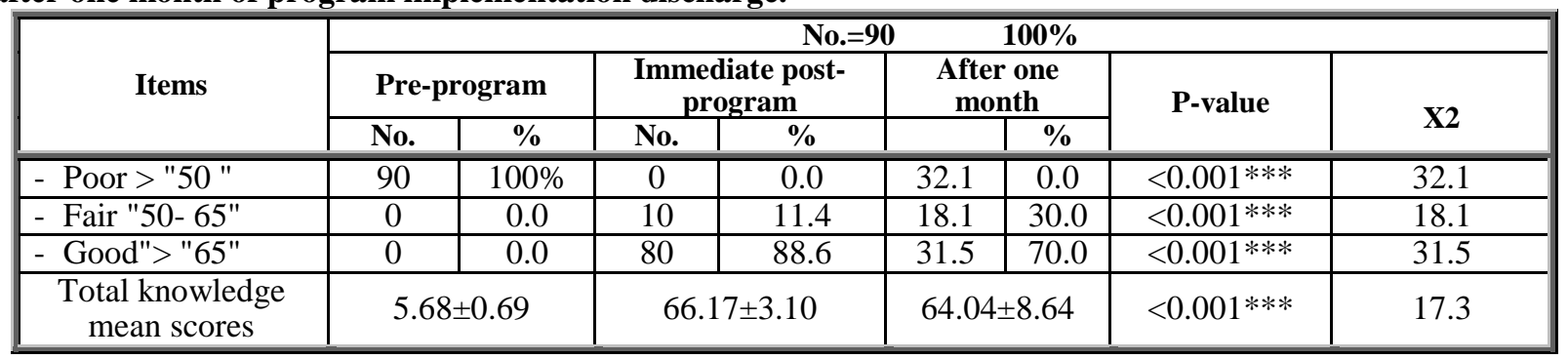

***A highly statistical significant difference $(P<0.000)$

Table (5): Frequency and percentage of distribution of the adults regarding equipment preparation for stoma care pre, immediate post, and after one month of program implementation discharge.

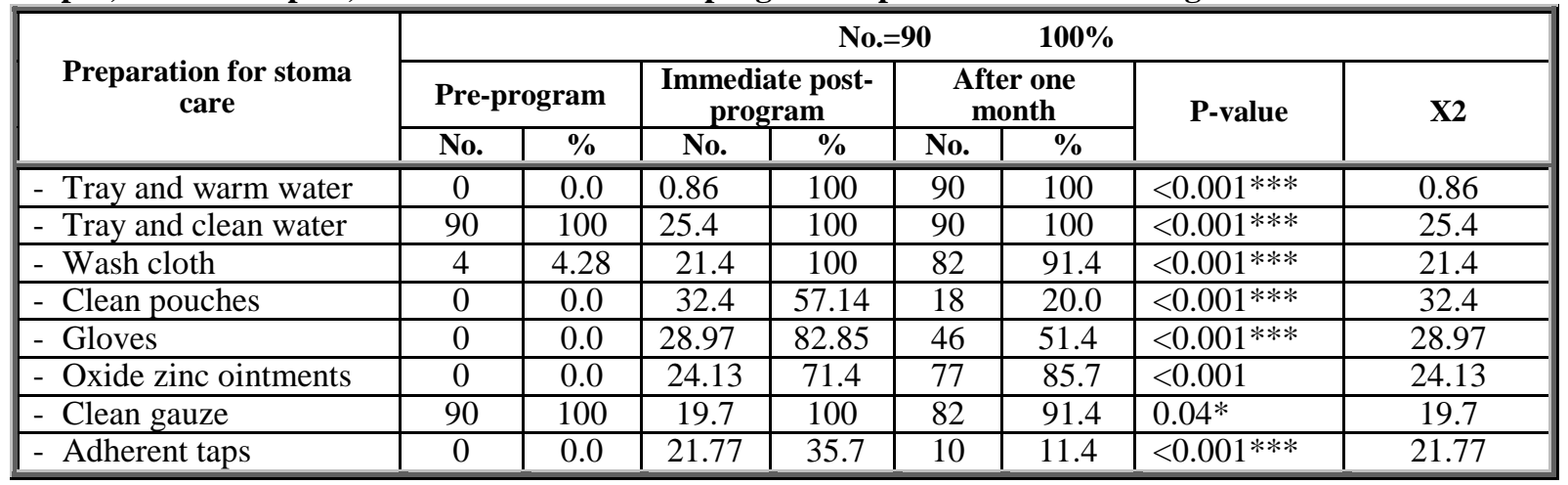

$* * * A$ highly statistical significant difference $(P<0.000)$

Table (6): Frequency and percentage of distribution of the adults regarding the stoma care technique pre, immediate post, and after one month of program implementation discharge.

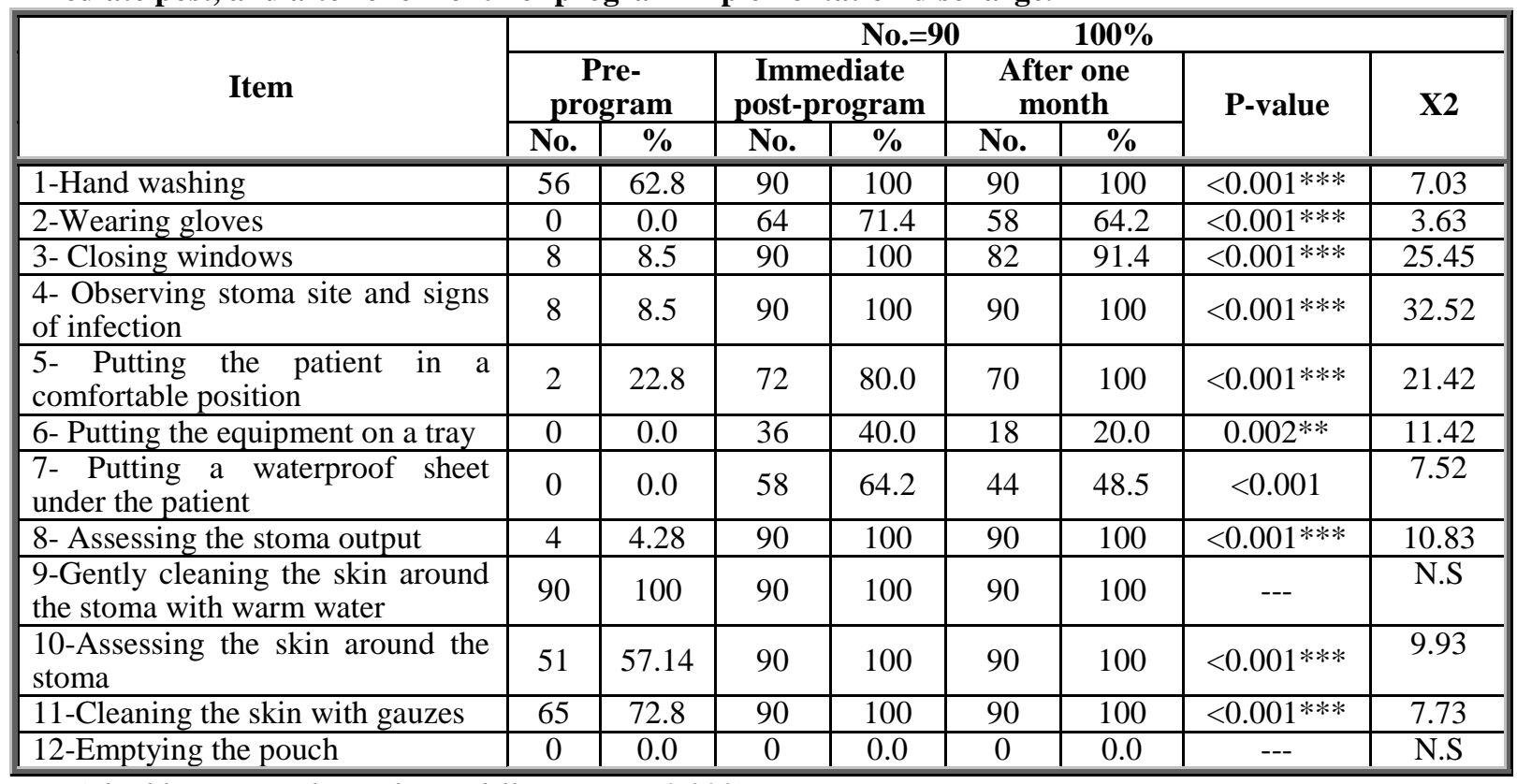

***A highly statistical significant difference $(P<0.000)$ 
Table (7): Total mean score of the studied adults' practice regarding equipment preparation and procedure of stoma care pre, immediate post, and after one month of program implementation discharge.

\begin{tabular}{|l|c|c|c|c|c|c|}
\hline \multirow{2}{*}{ Item } & \multicolumn{5}{c|}{ No.=90 } & \multicolumn{2}{c|}{ 100\% } \\
\cline { 2 - 7 } & Pre-program & $\begin{array}{c}\text { Immediate } \\
\text { post-program }\end{array}$ & $\begin{array}{c}\text { After one } \\
\text { month }\end{array}$ & P-value & $\begin{array}{c}\text { Total } \\
\text { score }\end{array}$ & X2 \\
\hline - Equipment preparation & $2.04 \pm 0.20$ & $6.48 \pm 1.40$ & $5.55 \pm 1.23$ & $0.000 * * *$ & 8 & 6.52 \\
\hline - Procedure of stoma care & $14.08 \pm 1.05$ & $20.57 \pm 0.811$ & $20.28 \pm 1.14$ & $0.000 * * *$ & 24 & 25.35 \\
\hline
\end{tabular}

$* * * A$ highly statistical significant difference $(P<0.000)$

Table (8): Comparison of adults' level of practice related to their stoma care pre, immediate post, and after one month of program implementation discharge.

\begin{tabular}{|c|c|c|c|c|c|c|c|c|}
\hline \multirow{3}{*}{ Items } & \multicolumn{8}{|c|}{ No. $=90$} \\
\hline & \multicolumn{2}{|c|}{ Pre-program } & \multicolumn{2}{|c|}{$\begin{array}{c}\text { Immediate post- } \\
\text { program }\end{array}$} & \multicolumn{2}{|c|}{ After one month } & \multirow[t]{2}{*}{ P-value } & \multirow[t]{2}{*}{$\mathbf{X} 2$} \\
\hline & No & $\%$ & No & $\%$ & No & $\%$ & & \\
\hline - Poor > "50" & 50 & $(55.7 \%)$ & 0 & 0.0 & $\overline{0}$ & 0.0 & $<0.001 * * *$ & 45.67 \\
\hline - Fair "50- 65" & 36 & $(40.0 \%)$ & 0 & 0.0 & 0 & 0.0 & $<0.001 * * *$ & 49.83 \\
\hline - Good"> "65" & 4 & $(4.28 \%)$ & 90 & $(100 \%)$ & 90 & $(100 \%)$ & $<0.001 * * *$ & 59.1 \\
\hline $\begin{array}{l}\text { Total practice } \\
\text { Mean scores }\end{array}$ & \multicolumn{2}{|c|}{$16.17 \pm 1.60$} & \multicolumn{2}{|c|}{$27.06 \pm 1.73$} & \multicolumn{2}{|c|}{$25.84 \pm 2.12$} & $<0.001 * * *$ & 61.45 \\
\hline
\end{tabular}

$* * * A$ highly statistical significant difference $(P<0.000)$

Table (9): Correlation coefficient between adults' total knowledge and practice scores regarding stoma care pre, immediate post, and after one month of program implementation discharge.

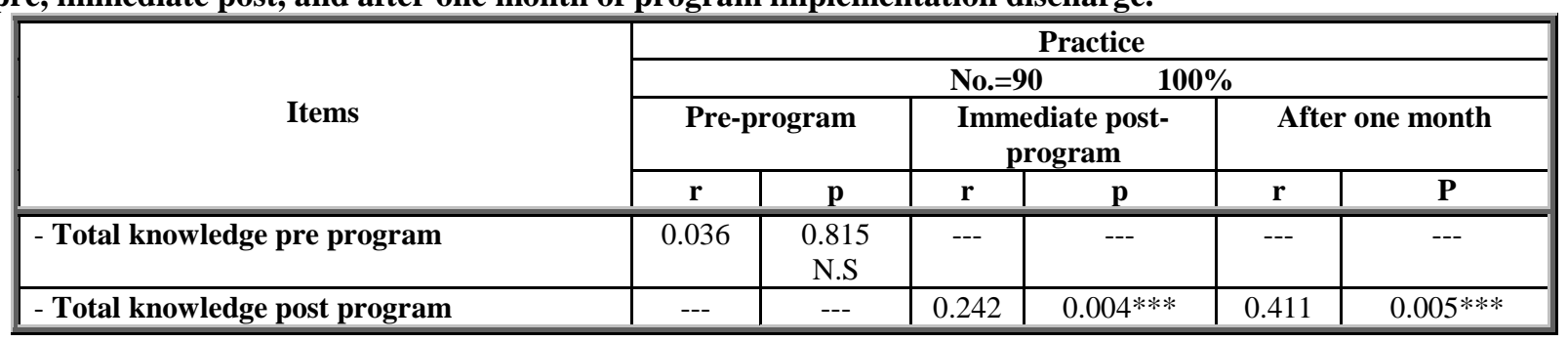

N.S=no statistical significant difference

Table (1): Described the characteristics of the studied patients; more than one third $(39.15 \%)$ of their ages ranged from 40-50 years, whereas their mean age was $47.9 \pm$ years. As regards to the level of education, less than one third of the respondents $(33.0 \%)$ were illiterate and $5.0 \%$ of them had university education. Regarding residence, it was found that $37.15 \%$ of the participants were from urban areas while $62.85 \%$ of them were from rural areas.

Figure (1): Showed that more than two thirds of the studied adults $(68.0 \%)$ were males and $32.0 \%$ were females.

Table (2): Displayed the distribution of the studied adult patients regarding their medical history; this table revealed that $63.0 \%$ of them had bowel cancer, and $94.0 \%$ of them had no family history for stoma while $6.0 \%$ had family history. Also, more than two thirds of the participants (67\%) had no history of previous hospitalization.

Table (3): Presented the patients' knowledge about stoma pre, post, and after one month of program implementation. This table pointed out that there was a highly significant difference between pre, post, and after one month of program implementation in relation to the studied adults' knowledge regarding stoma $(\mathrm{p}<0.001)$. The same table indicated that there was showed a minimal decrease in the adults' level of knowledge after one month of program implementation $(\mathrm{p}<0.001)$, in relation to causes of stoma, types of diet, and prescribed food and the precaution procedures that should be followed during food intake.

Table (4): Illustrated that there was a highly significant difference between the patients' level of knowledge pre, immediate post, and after one month of program implementation discharge regarding stoma care $(\mathrm{P}<0.001)$. There was a highly significant difference $(\mathrm{P}<0.001)$ in the adults' mean of total knowledge scores pre, immediate post, and after one month of program implementation discharge. 
Table (5): Showed that there was a highly significant difference $(\mathrm{P}<0.001)$ as regards to the patients' preparation of equipment for stoma care including tray and warm water, tray and clean water, wash cloth, clean pouches, gloves, oxide zinc ointments, and adherent taps pre, immediate post, and after one month of program implementation discharge. Regarding clean gauze, a statistical significant difference was found $(\mathrm{P}=0.04)$.

Table (6): Presented that there was an improvement regarding the procedure for stoma care pre, immediate post, and after one month of program implementation discharge where there were highly significant differences $(\mathrm{P}<0.001)$. As regards to all the steps of care as well as putting the equipment on a tray, there were a significant difference $(\mathrm{P}=0.002)$. Concerning gently cleaning the skin around the stoma with warm water and emptying the pouch, it was observed that there was no significant difference in the pre and post program implementation discharge.

Table (7): Reflected that there was a highly significant difference $(\mathrm{P}<0.001)$ pre, immediate post, and after one month of program implementation discharge about equipment preparation and procedure of stoma care.

Table (8): Indicated that there was a highly significant statistical difference $(\mathrm{P}<0.001)$ detected between the patients' practice level regarding stoma care at pre, post, and after one month of program implementation discharge.

Table (9): Revealed that there was a high significant statistical correlation between the patients' total knowledge and practice scores at post and after one month of program implementation discharge, respectively $(\mathrm{P}=0.004, \mathrm{P}=0.005)$.

\section{Discussion}

Stoma is a surgical opening created in the large intestine from the stomach, intestine, urinary bladder, kidney, or trachea (Breckman, 2012). Adults with stoma experience many changes after surgery that might affect their way of life. The aim of this study was to evaluate the effectiveness of self-management program about stoma care on the adult patients' knowledge and practice regarding stoma care.

The current study revealed that more than one third $(39.15 \%)$ of the patients' ages ranged from 40-50 years, whereas their mean age was $47.9 \pm$ years. This result agrees with Mohey et al., (2014) who studied the impact of the health education intervention for colostomy patients on their quality of life in Benha and revealed that two thirds of the sample were in the same age group. Moreover, this result agrees with the National Digestive Diseases Information Clearinghouse (2011) which reported that the majority of colostomies are found among people of this age. This was probably because those adults in the age group greater than 40 years have high risk factors for colon cancer. The present study results are similar to those of the study conducted by Magazi (2010) which was about the assessment of self-care practice among patients with colostomy, at the Faculty of Nursing, Zagazig University. This latter study reported that nearly half of the colostomy was in the age category 46-60 year olds.

The current study revealed that more than two thirds of the studied adults were males and $32.0 \%$ were females. These results are in agreement with the National Cancer Institute (2012) which stated in the incidence reported in Cairo, Egypt that the percentage of colostomies was higher in men than women. This was probably because of heavy smoking and the fast food that the Egyptian males consumed.

Regarding the patients' medical history, the current study revealed that approximately two thirds of them had bowel cancer, $94.0 \%$ had no history for stoma while $6.0 \%$ of them had family history. These results go in the same way with the study conducted by Erwin (2013) who reported on the ostomy care and rehabilitation in colorectal cancer. That researcher also mentioned that the causes for colostomy are disease conditions requiring the removal of the distal bowel as colorectal cancer.

Concerning the patients' knowledge about stoma pre, post, and after one month of program implementation discharge, the current study revealed that there was a highly significant improvement in the adult's knowledge as compared to pre-program knowledge. In the researcher's opinion, this was probably because many patients came from rural areas; and they had very little contact with the hospital after having been discharged. In addition, those patients' cultures prevented them from talking about these issues. Thus, a self-management program was essential to be educated to those patients about stoma care to improve their knowledge.

This finding was also consistent with the results of Pandey \& Dhungana (2013). These researchers conducted their study on knowledge and practice of stoma care among ostomates at Koirala Memorial Cancer Hospital. They carried out their interventional study on patients with permanent colostomy in China to assess their knowledge about colostomy care, colostomy products, prevention and treatment of complications, types and storage of colostomy bags, and colostomy irrigation. The result showed that the patients' knowledge improved after the intervention. The current study revealed that there was a highly significant difference $(\mathrm{p}=<0.000)$ in the adults' mean of total knowledge scores pre, immediate post, and 
after one month of program implementation discharge. This was probably because the effectiveness of the program intervention reflected its importance and introduced the intervention about stoma care to the adult patients based on their needs. This result is in accordance with the study conducted by Culha et al., (2016) who reported on the effectiveness of self-care education on patients with stoma. Their patients' knowledge scores about stoma given in the first meeting with the study and the control patient groups were not significantly different from each other. In the last meeting, it was determined that the stoma knowledge scores of the study group individuals were significantly higher than the scores of the control group individuals.

The current study result indicated that there was a highly significant difference $(p=<0.000)$ detected between adults' practice in pre, post, and after one month of program implementation discharge. This result reflected the importance of the program implementation about stoma care and the urgent need of the adult patients to increase their awareness and knowledge of the adequate practice of stoma care for protecting themselves as a method of prevention against stoma problems and infection. In the same line, Hegazy et al., (2014) reported that there was a significant improvement that was indicated in the post education guidelines as compared to the preassessment.

The current study revealed that there was a highly significant statistical correlation between the patients' total knowledge scores and their practice at post and after one month of program implementation discharge, respectively $(\mathrm{P}=0.004, \mathrm{P}=0.005)$. This finding is in accordance with Stoke et al., (2017) who stated that patient education had a great improvement in the physiological aspects of stoma patients, especially in reducing physical pain and the incidence of complications. In addition, this reflected the positive effect of the self-management program on the patients with stoma. This provided the knowledge and emphasized that teaching self-care before hospital discharge may improve the stoma care knowledge and skills of the adult patients in order to help them with this management option.

\section{Conclusion}

In the light of the study findings, it can be concluded that a high significant statistical difference was detected between adult patients' knowledge and practice pre, post, and after one month of program implementation discharge $(p=<0.000)$. The adult patients' knowledge was deficit concerning stoma, diet, home care, and follow up in different age groups before the program. However, after the program implementation, the study findings reflected that there were highly statistical differences in improving patients' knowledge and practice regarding their stoma care.

\section{Recommendations}

Based on the findings of the current study, the following recommendations are proposed:

1. The adult patients with stoma should receive adequate and continuous education, simulation, and counseling regarding ostomy self-care, lifestyle changes, and self-efficacy.

2. The medical and surgical nurse, as a health educator, should provide the adult patients with adequate training and application on stoma care.

3. Follow up, for updating knowledge about care and further complications, is needed to be carried out by community health nurses. They should provide adult patients with appropriate care through verbal and written instructions regarding home management for stoma.

\section{References}

- American Cancer Society, (2017): Treatments and side effects/ Physical Side Effects/ Ostomies/ Urostomy Guide/Index. Accessed June 8, 2011. http://www.cancer.org/Treatment.

- Andrade, S., De Sousa, M., de Brito, K., Matos, S., Coelh, S., \& Oliveira, S., (2016): Sociodemographic and clinical features and quality of life in atomized patients, $\mathrm{j}$ coloproctol (rio j); 3 6(1): 27-33.

- Beitz, J., (2004): Gastrointestinal etiologies leading to a fecal diversion. Disease of colon and rectum: 136-159.

- Breckman, B., (2012): Stoma care and rehabilitation. Oxford, Elsevier Churchill Livingstone. Gastrointestinal Nursing; 5: 9, 32-39.

- Culha, I., Kosgeroglu, N., \& Bolluk, O., (2016): Effectiveness of Self-care Education on Patients with Stomas, IOSR Journal of Nursing and Health Science, 5(2): 70-76.

- Erwin, P., (2013): Ostomy care and rehabilitation in colorectal cancer. Oncology nursing journal, 22(3): 174-77.

- Fulham J., (2018): A guide to caring for patients with a newly formed stoma in the acute hospital setting. Gastrointestinal nursing, p: 6 (8).

- Hegazy, S., Ali, Z., Mahmoud, A., \& Abou-Zeid, A., (2014): Outcomes of Educational Guidelines on Awareness and Self - Efficacy among Patients with Permanent Colostomy, New York Science Journal; 7(3): 25-32.

- Magazi, N. (2010): Assessment of self-care practices among patients with colostomy. 
Unpublished Master thesis, Faculty of Nursing, Zagazig University pp.73-90.

- Mohey El Din, M., Hasan, S., Abdel Hameed, H., \& Abdel Aziz, M., (2014): Impact of Health Education Intervention for Colostomy Patients on their Quality of Life at Benha, thesis of doctora degree in nursing, faculty of nursing, Benha Universty, pp. 98.

- National Cancer Institute, (2012): Incidence Reported. Cairo, Egypt. Available at: http:// www. Your Cancer today. Com/ cancers/ Rectal/127. Retrieved on: 23/8/2013.

- National Cancer Institute, (2017): Incidence Reported. Cairo, Egypt. Available at: http:// www. Your Cancer today. Com/ cancers/ Rectal/127. Retrieved on: 23/8/2013.

- National Digestive Diseases Information Clearinghouse (2011): Ileostomy, colostomy and ileoanal reservoir surgery. Available at: www.uoaa.orghttp://www.cancer research.com.

- Pandey, R., \& Dhungana, S., (2013): Knowledge and practice of stoma care among ostomates at b.p.koirala memorial cancer hospital, Journal of Nobel Medical College, 4(1), Issue 7, pp 36: 45.

- Ran, L., Jiang, X., Qian, E., Kong, H., Wang, X., \& Liu, Q., (2016): Quality of life, self-care knowledge access, and self -care needs in patients with colon stomas one month post-surgery in a Chinese Tumor Hospital, international journal of nursing sciences 322 e258.

- Salvadalena, G., (2008): Incidence of complications of the stoma and peristomal skin among individuals with colostomy, ileostomy and urostomy. Journal of Wound, Ostomy and Continence Nursing, 35(6), 596-607.

- Stokes, A., Tice, S., Follett, S., Paskey, D., Abraham, L., Bealer, C., Keister, H., Koltun, W., \& Puleo, F., (2017): Institution of a Preoperative Stoma Education Group Class Decreases Rate of Peri-stomal Complications in New Stoma Patients. Journal Wound Ostomy Continence Nursing, 44(4), 363-367. 